\title{
Corrosion evaluation of machined surface in aviation aluminum alloy under simulated service environment
}

\author{
Xiuli Fü ${ }^{1, a}$, Ying Meng ${ }^{2, b}$ and Wentao Liu $^{2, c}$
}

School of Mechanical Engineering, University of Jinan, Jinan 250022, China.

ame_fuxl@ujn.edu.cn, ${ }^{\mathrm{b}}$ mengy@163.com, ${ }^{\mathrm{c}} \mathrm{me}$ _liuwt@ujn.edu.cn

Keywords: Aluminum alloy, corrosion damage, machined surface, service environment.

\begin{abstract}
Based on evaluation method of corrosion damage, the processing surface corrosion resistance test has completed under different cutting parameters with the salt spray corrosion test machine. The corrosion damage of machined surface was detected by means of microcosmic-test. The effect of cutting parameters on corrosion resistance was analyzed during High-speed cutting process under simulated marine atmospheric environment. The experiment results show that the corrosion process of the processed surface is relatively slow at first. However the corrosion progress has accelerated tendency after 600 hours. The machined surface of cutting speed $4000 \mathrm{~m} / \mathrm{min}$ has satisfied corrosion resistance. The corrosion morphology of machined surface was obtained and analyzed. When the cutting speed exceeds a certain value $4000 \mathrm{~m} / \mathrm{min}$, the growth trend of micro cracks increase remarkably. The development and diffusion of corrosion pits is carried out along the direction of the tool marks, until the micro cracks appears in machined surface layer.
\end{abstract}

\section{Introduction}

High strength aluminum alloy 7050-T7451 has been widely used in aviation for high strength, hardness and toughness.Its performance is shown in Table $1^{[1]}$.

Table 1 Modulus and properties of aerospace aluminum alloy 7050-T7451 in normal temperature

\begin{tabular}{ccccc}
\hline $\begin{array}{c}\text { Yield strength } \\
\left(25^{\circ} \mathrm{C} / \mathrm{MPa}\right)\end{array}$ & $\begin{array}{c}\text { Tensile strength } \\
\left(25^{\circ} \mathrm{C} / \mathrm{MPa}\right)\end{array}$ & $\begin{array}{c}\text { Thermal expansion coefficient } \\
\left(20 \sim 100^{\circ} \mathrm{C}\right)\end{array}$ & $\begin{array}{c}\text { Density } \\
\left(\mathrm{kg} / \mathrm{m}^{3}\right)\end{array}$ & $\begin{array}{c}\text { Melting range } \\
\left({ }^{\circ} \mathrm{C}\right)\end{array}$ \\
\hline 455 & 510 & 23.5 & 2810 & $490-630$ \\
\hline
\end{tabular}

High-speed cutting surface of the work piece is shown in Fig. 1 as $v=1200 \mathrm{~m} / \mathrm{min}, f_{z}=0.25 \mathrm{~mm} / \mathrm{z}$, $a_{p}=1.5 \mathrm{~mm}, a_{e}=10 \mathrm{~mm}$. Cutting metamorphic layer which includes oxide film, thermal metamorphic zone and plastic reformatting zone can be seen clearly from microcosmic cutting surface. Deteriorated layer exist some micro defects such as dislocation, grain distortion and micro cracks, which have important influence on precision, wear resistance and corrosion resistance of work piece surface.

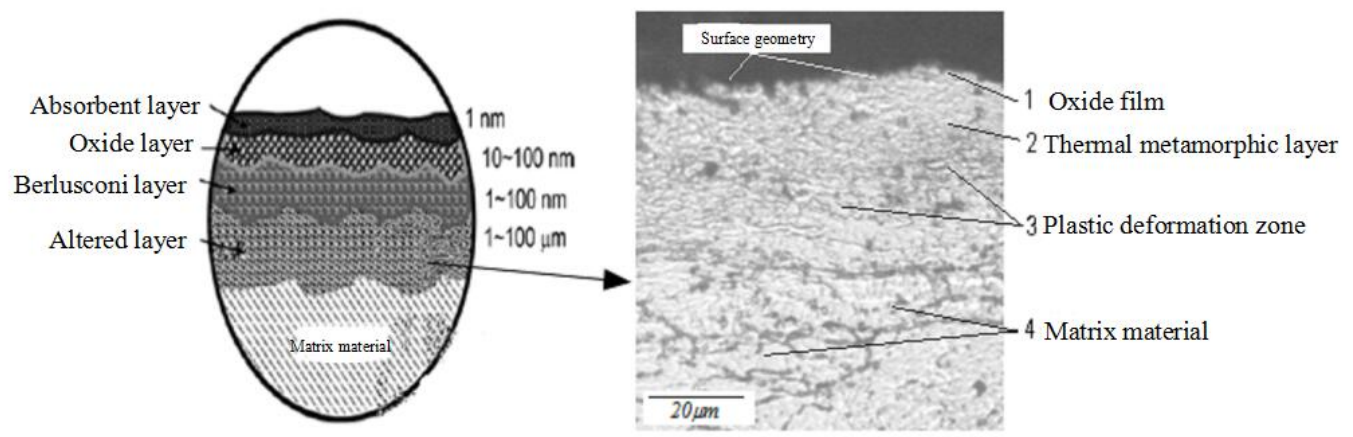

Fig. 1 Diagram microstructure of machined surface layer with SEM

Coastal salt fog atmosphere is the most severe in the process of aircraft service.Therefore, it is an important component for aeronautical components service performance to analyze the influence of different process parameters on the corrosion resistance under simulated marine atmosphere. With salt spray corrosion test machine, the utmost performance test of processed surface is finished under different cutting speeds and the effects of cutting parameters on corrosion resistance during high speed cutting process are analyzed under simulated marine atmospheric environment. 


\section{Corrosion evaluation and experiment}

\subsection{Corrosion evaluation system}

The rate of corrosion damage is an index to describe the speed of metal corrosion in the process of metallic corrosion which represents the degree of corrosion in the unit time. Corrosion damage degree of work piece was evaluated based on the average depth of the corrosion damage and the degree of the surface corrosion damage ${ }^{[2]}$.

1) average depth of corrosion damage $d_{a}$ :

$$
d_{a}=\frac{1}{\mathrm{n}} \sum_{i=1}^{n} d_{i}
$$

Where $n$ is the measured number of corrosion pits, $d_{i}$ is the depth of corrosion pits.

2) corrosion damage degree $\alpha$ :

$$
\alpha=\frac{1}{A} \sum_{i=1}^{n} A_{\mathrm{pi}} \times 100 \%
$$

Where $n$ is the number of corrosion pits; $A$ is the corrosion area, for circular corrosion pits, $A_{p i}=\pi d_{r}^{2} / 4$, for elliptical corrosion pits, $A_{p i}=\pi d_{r 1} d_{r 2} / 4, d_{r}$ is the corrosion pit diameter, $d_{r 1}$ is the elliptical hole long axis, where $d_{r 2}$ is the minor axis.

\subsection{Corrosion test}

Ratio of the corrosive liquid is the main reference to the real sea water because of the simulated marine atmospheric salt fog service environment. The specific solution composition is shown in Table $2^{[3]}$. The PH of corrosive liquid showed alkaline basically maintained between 7.9-8.4, and application of accurate $\mathrm{PH}$ test paper to detect hydrochloric acid and sodium carbonate to achieve $\mathrm{pH}$ adjustment.

Table 2 Composition of salt spray corrosion solution

\begin{tabular}{ccccccc}
\hline Salt composition & $\mathrm{NaCl}$ & $\mathrm{MgCl}_{2}$ & $\mathrm{MgSO}_{4}$ & $\mathrm{~K}_{2} \mathrm{SO}_{4}$ & $\mathrm{CaSO}_{4}$ & $\mathrm{CaCO}_{3}$ \\
\hline Quality (g/Kg) & 27.2 & 3.8 & 1.7 & 0.9 & 1.2 & 0.1 \\
Percentage (\%) & 77.7 & 10.9 & 4.9 & 3.6 & 2.5 & 0.3 \\
\hline
\end{tabular}

\subsection{Salt spray test}

In order to simulate service environment, the corrosion rate of salt spray corrosion test chamber is adjusted and temperature is controlled as service conditions. The salt spray test chamber should run for one hour before experiment so that salt fog is filled with the whole test chamber which ensures the accuracy of the experiment. The cutting parameters are shown in Table 3.

Table 3 Parameter design of cutting test

\begin{tabular}{ccccc}
\hline Cutting parameters & $\begin{array}{c}\text { Cutting speed } \\
v(\mathrm{~m} / \mathrm{min})\end{array}$ & $\begin{array}{c}\text { Feed rate } \\
f_{z}(\mathrm{~mm} / \mathrm{z})\end{array}$ & $\begin{array}{c}\text { Radial cutting width } \\
a_{e}(\mathrm{~mm})\end{array}$ & $\begin{array}{c}\text { Axial cutting depth } \\
a_{p}(\mathrm{~mm})\end{array}$ \\
\hline \multirow{2}{*}{ Numerical } & $\begin{array}{c}\text { 2500、3000、3500 } \\
\text { 4000、4500、5000 }\end{array}$ & 0.1 & 20 & 0.5 \\
\hline
\end{tabular}

Salt spray corrosion test was carried out on processed surface with high speed cutting experiment and the non processed surface was treated with paint. The temperature in test chamber was controlled at $35 \pm 2^{\circ} \mathrm{C}$. Test piece flatted in test chamber with salt spray landing speed each $1 \sim 2 \mathrm{ml} / \mathrm{h}$ on $100 \mathrm{~cm}^{2}$ lasting for 1200 hours, then observation of the samples after corrosion in the microscope every 200 hours.

\section{Change regulation of corrosion damage}

Based on theoretical formula of corrosion evaluation system and optical microscope, the size and depth of corrosion pits on corrosion surface were measured and calculated as shown in Fig.2. The corrosion damage was calculated by measuring the long and short axis lengths of the corrosion pits in Fig.2. The depth of corrosion can be directly get by using optical 3D imaging technique. 


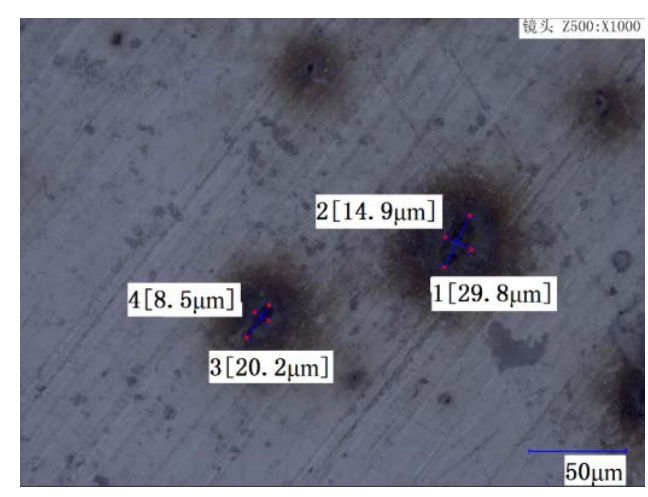

Fig.2 Measurement of corrosion pit size

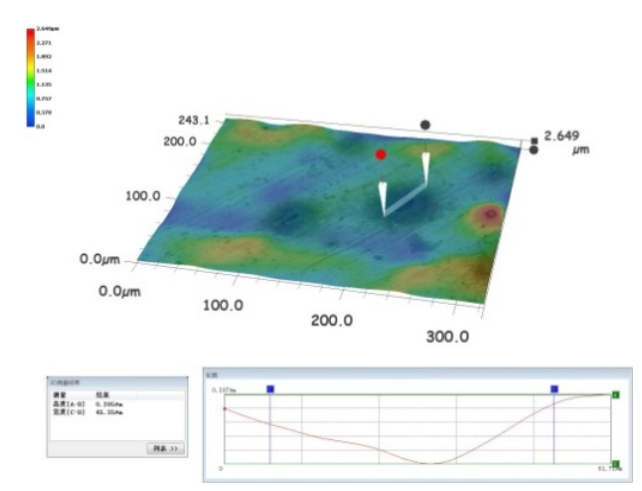

Fig.3 Diagram of corrosion pit depth measurement

The change regulation of work piece corrosion damage with corrosion cycle under different cutting speed and time though the measurement of corrosion pit depth, area and the evaluation of corrosion damage degree, as shown in Fig. 4 and Fig.5.Fig. 4 shows the corrosion characteristics of processed surface at different cutting speeds. The corrosion degree of the work piece is relatively flat at initial stage.However the corrosion progress has accelerated tendency and the corrosion depth changes significantly after 600 hours. The corrosion pit depth is more and more deeper with the increase of corrosion time.

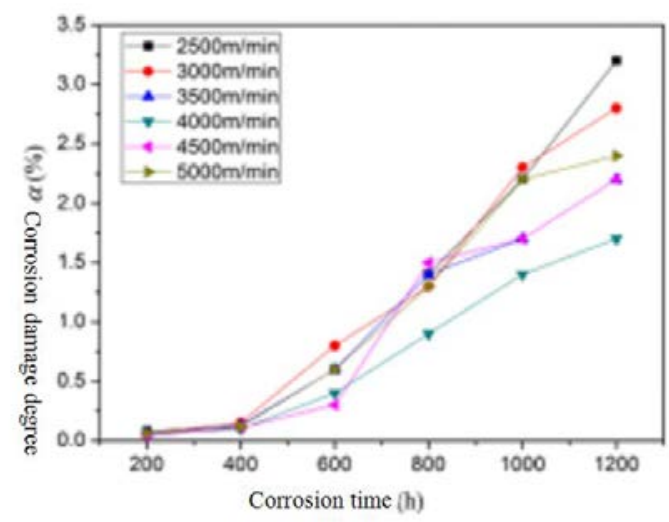

Fig. 4 Variation of Corrosion damage with time

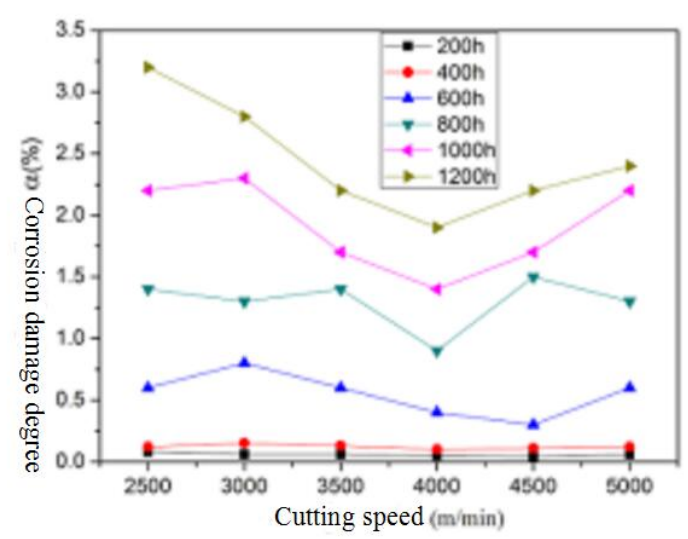

Fig. 5 Variation of Corrosion damage with speed

Fig. 5 shows the change tendency of the corrosion damage degree with the cutting speed under different corrosion cycles. Corrosion resistance of processed surface during high speed and low speed cutting process has no obvious regularity. The corrosion resistance gets better after cutting speed $4000 \mathrm{~m} / \mathrm{min}$. The processed surface with severe plastic deformation in high speed cutting process forms a precise metamorphic layer which the surface dislocation density increases and grain achieves refinement. These results can exert protective effect of the processed surface,and the corrosion resistance of the modified layer is strengthened. Therefore, with the increment of cutting speed, the corrosion resistance of surface is enhanced at cutting speed $2500 \sim 4000 \mathrm{~m} / \mathrm{min}$. However, the processed surface appears micro cracks which is difficult to detect with cutting speed continues to rise. The appearance of micro cracks provides the storage space for the corrosion liquid which makes the corrosion environment more severe. And micro cracks become the starting point of corrosion pits. Therefore, as the cutting speed continues to increase, the processed surface corrosion resistance is reduced.

Fig.6 shows topography of machined surface at cutting speed $v=2500 \mathrm{~m} / \mathrm{min}$ and corrosion surface topography under different corrosion time. With the increment of cutting speed and the vibration intensifies, more micro cracks exist at processed surface in high speed cutting process, especially along the direction of tool marks. These micro defects provide storage space for the corrosion medium and accelerate the corrosion damage process. According to the location of corrosion pits, it can infer that corrosion pits and the direction of tool marks have a certain relationship.

The corrosion development shows the tendency along the direction of tool marks at first and then develops around.The corrosion damage degree is obviously worse after the cutting speed $4000 \mathrm{~m} / \mathrm{min}$. 
Therefore cutting parameters and cutting path have certain influence on the formation of surface corrosion damage.

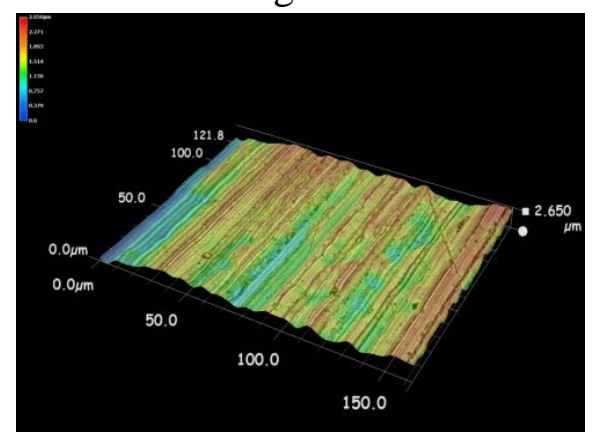

a) 3D topography of surface

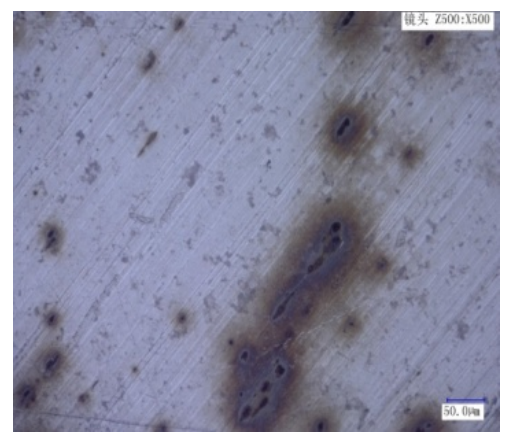

b) after $600 \mathrm{~h}$ corrosion

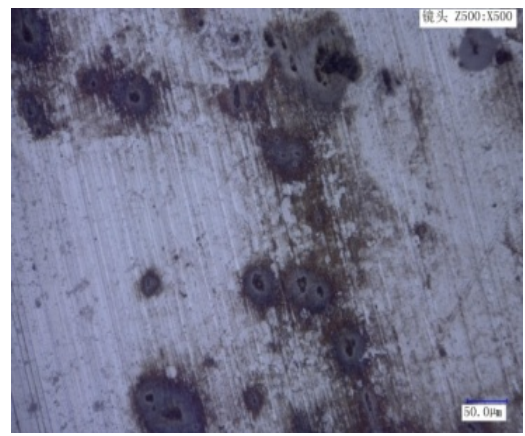

c) after $1200 \mathrm{~h}$ corrosion

Fig.6 Optical topography and corrosion characteristics of processed surface

\section{Summary}

Under the condition of high speed machining and based on the evaluation system of corrosion damage, the influence of different cutting speed on the corrosion damage of the machined surface is studied by using high speed cutting machine tools and salt spray corrosion test chamber. The conclusions are as follows:

1) The experiment results show that the corrosion process of the processed surface is relatively slow at first. However the corrosion progress has accelerated tendency after 600 hours. The machined surface of cutting speed $4000 \mathrm{~m} / \mathrm{min}$ for alumnium alloy $7050-\mathrm{T} 7451$ has satisfied corrosion resistance.

2) The development and diffusion of corrosion pits is carried out along the direction of tool marks through the microscopic observation of the surface corrosion phenomenon .

3) Through the analysis of corrosion phenomenon of processed surface,it can be inferred that there are some micro cracks on processed surface and micro cracks are not obvious when cutting speed is not high. Micro cracks go into more until cutting speed reaches a certain value $4000 \mathrm{~m} / \mathrm{min}$. According to the development path of the corrosion pit, the micro crack is caused by the pull of the surface material in cutting process and along the direction of tool marks.

\section{Acknowledgements}

This work is supported by the National Natural Science Foundation of China (Grant No.51675230), Major Science and Technology Program (2012ZX04004011-04) of China and Natural Science Fund project in Shandong province (ZR2015EL028).

\section{References}

[1] LIU Yunzhong, LI Zhilong, GU Caixin. Deformation Behavior and Microstructure Evolution of 7050 Aluminum Alloy During Semi-solid State Compression Process[J]. Acta Metallurgica Sinica, 3013, 49(12):1597-1603.

[2] Ömer Özgür Çapraz, Shinsuke Ide, Pranav Shrotriya, Kurt R. Hebert. Tensile stress and plastic deformation in aluminum induced by aqueous corrosion[J]. Acta Materialia, 2016, 115: 434-441.

[3] QI Xing, SONG Ren-guo, WANG Chao, LI Hai, QIAO Li-jie, SU Yan-jing, CHU Wu-yang. Effects of cathodic polarization on stress corrosion behavior of 7050 aluminum alloy[J]. The Chinese Journal of Nonferrous Metals,2014,24(3):631-636.

[4] Eliezer, A Haddad, J Garcia, A Valdez, B Schorr M. Corrosion of Naval Aluminum in Seawater[J]. Materials Performance,2010,499(9):62-66. 